\title{
News from ABC: Editorial board and features
}

\author{
Steffen Pauly
}

Published online: 22 November 2012

(C) Springer-Verlag Berlin Heidelberg 2012

After a year of celebrating the tenth anniversary of Analytical and Bioanalytical Chemistry ( $\mathrm{ABC})$, but also intense thinking about the further development of the journal, we would like to share some changes with our readers and authors.

First, the editors and the editorial office would like to express our sincere thanks to Maciej Jarosz (Fig. 1) for serving as Regional Editor Central Europe for the past 3 years. He has helped to achieve a smooth merger of the journal Chemia Analityczna/Chemical Analysis with ABC and to successfully promote $\mathrm{ABC}$ in the analytical science communities of central Europe, resulting, e.g., in two special issues on analytical and bioanalytical science in Poland (volume 399, issue 9 and volume 402, issue 7) as well as a significant increase in the number of published articles originating from central Europe. Therefore, we are very pleased that Maciej Jarosz will continue to support ABC as a member of the International Advisory Board.

Fig. 1 Maciej Jarosz, Warsaw University of Technology

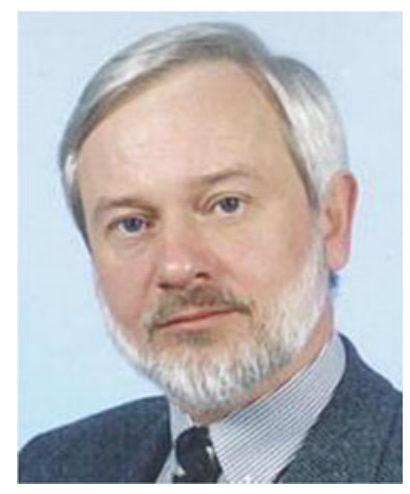

S. Pauly $(\bowtie)$

Analytical and Bioanalytical Chemistry, Springer,

Tiergartenstrasse 17,

69121 Heidelberg, Germany

e-mail: steffen.pauly@springer.com
We are also indebted to Cynthia Larive, who for many years has shaped our educational column "ABCs of Teaching Analytical Science" and now steps down as column editor. She will be succeeded by Thomas Wenzel of Bates College, Lewiston, Maine (USA), but continues as a member of the International Advisory Board of ABC. Further changes to the educational columns of $\mathrm{ABC}$ will be introduced by Cynthia Larive in her editorial "Happy New Yearrenewal, welcome, and farewell" in this issue.

The "Aims and Scope," which is posted on the journal's homepage and printed in every issue, defines the criteria that papers have to meet to be considered for publication in $\mathrm{ABC}$. To further improve the reputation and impact of the journal, the "Aims and Scope" of ABC has now been revised. The editors wish to point out more clearly that we are looking for excellent, high-impact research articles while maintaining a broad scope covering both novel methodological developments and truly innovative applications. Authors are advised to consult the "Aims and Scope" prior to submitting a contribution.

Topical paper collections and special issues continue to be a very well received feature of $\mathrm{ABC}$. In the past, they sometimes also included conference-based special issues with open and nonselective invitation of all conference participants to submit papers to $\mathrm{ABC}$. In view of the revised "Aims and Scope" and in order to further improve the quality of the topical paper collections, with rare exceptions such conference-based special issues will no longer be produced. As before, however, the editors warmly invite guest editors to organize paper collections on topics of high interest from the field of analytical and bioanalytical science with contributions from selected, outstanding experts.

There have also been changes to the types of papers that are published in $\mathrm{ABC}$. Urgent communications of important preliminary results that are very original, of high interest, and likely to have a significant impact on the analytical 
community can now be published as a "Rapid Communication." The results of peer review need to support the urgency of publication ahead of a full research article, which should usually follow a "Rapid Communication" to provide complete information. The editors strongly discourage fragmentation of a substantial body of work into a number of short publications. "Short Communications" have therefore been discontinued.

For publication of noteworthy improvements, significant novel applications or practical solutions to problems with regard to an (established) analytical technique, ABC now offers the "Note" category. For articles in this category, we stipulate a maximum length of 2,000 words with two figures and/or tables, as well as a maximum of five key references. Although the previous "Technical Note" implied content of a technical nature, the scope of a "Note" is meant to be broader. For a detailed description, authors are advised to consult "What type is my paper?" on the $\mathrm{ABC}$ homepage at http://www.springer.com/abc.

We are confident that the revised "Aims and Scope" as well as the new paper types will further raise the profile of $\mathrm{ABC}$. These changes build on previous amendments which have facilitated the outstanding development of the journal in the past few years. This development is evidenced, e g., by the immediacy index (Fig. 2), which relates the number of citations in a specific year to the number of articles published in that year.

Besides highly cited articles, for many years colorful, "science-art" covers have been an attractive feature of the journal. In 2012, for the first time we invited readers and authors of $\mathrm{ABC}$ to choose the most attractive cover from the issues published in 2011. We are pleased to announce that in 2013 there is also a choice between the covers from the
ABC Immediacy Index

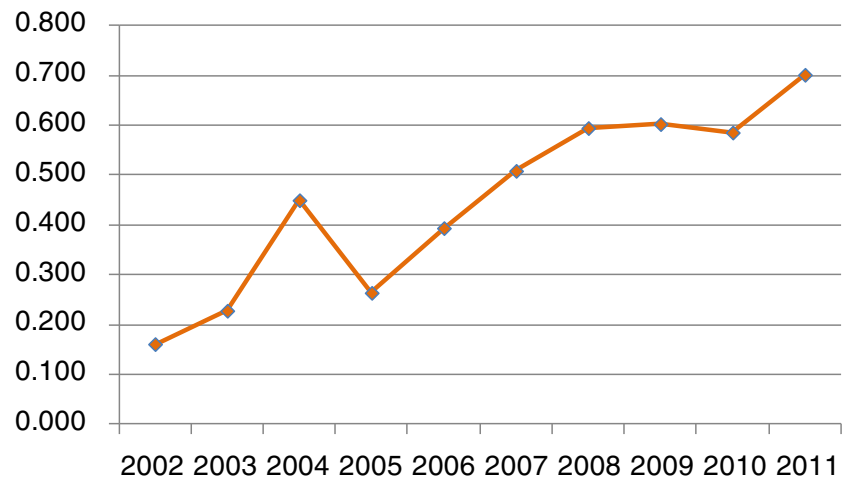

Fig. 2 Development of the immediacy index of Analytical and Bioanalytical Chemistry $(A B C)$ from 2002 to 2011

previous year, as well as a chance to win an iPad in our cover raffle. For more information, consult http:// www.springer.com/abc. Speaking of covers, the new cover design of $\mathrm{ABC}$ from 2013 pays due tribute to the eight European chemical societies which are co-owners of $A B C$, i.e., the German Chemical Society (GDCh), the Chemical Society of France (SFC), the Spanish Society for Analytical Chemistry (SEQA), the Royal Spanish Society of Chemistry (RSEQ), the Austrian Society for Analytical Chemistry (ASAC), the Division of Analytical Chemistry of the Swiss Chemical Society (DAC/SCS), the Italian Chemical Society (SCI), and the Polish Chemical Society (PTChem). Their logos are now featured on the front cover.

On behalf of the editors

Steffen Pauly 